\title{
Beneficial Effect of Troglitazone, an Insulin-Sensitizing Antidiabetic Agent, on Coronary Circulation in Patients With Non-Insulin-Dependent Diabetes Mellitus
}

\author{
Michihito Sekiya, MD; Jun Suzuki, MD; Kouki Watanabe, MD*; \\ Junichi Funada, MD; Takashi Otani, MD; Hiroshi Akutsu, MD
}

\begin{abstract}
Evidence is increasing for small vessel remodeling and disturbance of endothelium-dependent vasodilation in diabetic patients. Insulin increases vascular wall thickening and produces endothelial dysfunction. Troglitazone, a new insulin-sensitizer antidiabetic agent, is considered to reduce plasma insulin level and the present study assessed its effect on the coronary circulation of the patients with non-insulin-dependent diabetes mellitus (NIDDM). Analysis of the myocardial washout rate with adenosine triphosphate-stress thallium-201 scintigraphy was used to estimate coronary circulation, and for estimation of insulin sensitivity, the homeostasis model insulin resistance index (HOMA-R) was calculated. Patients were treated with monotherapy of either troglitazone (200 $\mathrm{mg}$ bid, $\mathrm{n}=12)$ or glibenclamide ( $2.5 \mathrm{mg}$ daily, $\mathrm{n}=12)$ for 3 months. Age-, sex- and risk factors-matched subjects without NIDDM were employed as a control. Fasting plasma glucose and hemoglobin Aic were similarly decreased by troglitazone or glibenclamide. Plasma insulin level $(\mathrm{pmol} / \mathrm{L})$ decreased from $66.6 \pm 10.8$ to $39.0 \pm 7.2$ with troglitazone, but was unchanged by glibenclamide $(58.8 \pm 7.2$ to $66.0 \pm 10.8)$. The diabetic groups had a significantly lower washout rate than controls, which was improved by troglitazone, but not by glibenclamide. In addition, the increase in washout rate correlated significantly with the decrease in HOMA-R in the troglitazone group. In conclusion, troglitazone can restore coronary circulation by improving insulin resistance in patients with NIDDM. (Jpn Circ J 2001; 65: 487-490)
\end{abstract}

Key Words: Coronary circulation; Insulin resistance; Non-insulin-dependent diabetes mellitus; Troglitazone; Washout rate

$\mathbf{P}$ atients with non-insulin-dependent diabetes mellitus (NIDDM) frequently have signs of myocardial ischemia and congestive heart failure (diabetic cardiomyopathy) in the absence of obstructive coronary disease ${ }^{-4}$ It has been reported that wall thickening and lumen narrowing of the intramural coronary microvasculature may result in inadequate coronary flow reserve capacity by reducing the maximal area of the coronary microcirculation:-7 In addition, evidence is increasing for disturbance of endothelium-dependent vasodilation in conduit as well as resistant coronary arteries in patients with NIDDM 8.9 Thus, abnormal coronary circulation may contribute to the myocardial ischemia or diabetic cardiomyopathy.

The pathophysiology of NIDDM is complex, but insulin resistance is a characteristic feature and contributes importantly to the hyperglycemic diabetic state 10,11 Insulin has various biological actions on the vessel wall, such as proliferation of vascular smooth muscle cells ${ }^{12}$ or enhancement of the intracellular $\mathrm{Na}^{+} / \mathrm{H}^{+}$pump!3 Therefore, hyperinsulinemia caused by insulin resistance may increase wall thickening and produce endothelial dysfunction.

Troglitazone is a newly developed antidiabetic agent that improves insulin resistance ${ }^{14-16}$ and its anti-diabetic and insulin suppressive effects have been confirmed in patients

(Received December 27, 2000; revised manuscript received February 23, 2001; accepted February 28, 2001)

Department of Cardiology, Ehime National Hospital and *Department of Internal Medicine, Saiseikai Saijo Hospital, Ehime, Japan

Mailing address: Michihito Sekiya, MD, Department of Cardiology, Ehime National Hospital, 366 Shigenobu, Onsen-gun, Ehime 7910204, Japan. E-mail: msekiya@ehime-nh.go.jp with NIDDM. The present study assessed the effect of troglitazone on coronary circulation in patients with NIDDM, using adenosine triphosphate disodium (ATP)-stress thallium-201 $\left({ }^{201} \mathrm{Tl}\right)$ myocardial scintigraphy, which has been reported to be an useful tool for non-invasive assessment of coronary perfusion ${ }^{17,18}$ and coronary flow reserve! 19,20

\section{Methods}

\section{Study Patients}

The study group consisted of 24 outpatients with NIDDM (15 men, 9 women; aged 45-71 years (mean \pm SD) 60 \pm 9 years). All patients had angiographically normal coronary arteries. The enrollment criteria of NIDDM were fasting plasma glucose $(\mathrm{FPG}) \geq 7.00 \mathrm{mmol} / \mathrm{L}$ and a fasting insulin level (IRI) $\geq 30 \mathrm{pmol} / \mathrm{L}$ on at least 2 separate visits. In addition, NIDDM had been newly diagnosed in all the patients, who had never been treated with antidiabetic drugs. Patients with left ventricular hypertrophy, left ventricular dysfunction, a history of myocardial infarction, or valvular heart disease were excluded from the study. We also selected 12 subjects without NIDDM, matched in age, sex, and risk factors except DM as a control group.

\section{Study Protocol}

Patients were randomized to 2 groups for either troglitazone therapy ( $200 \mathrm{mg}$ bid, $\mathrm{n}=12$ ) or glibenclamide therapy ( $2.5 \mathrm{mg}$ daily, $\mathrm{n}=12$ ), and the drugs were administered orally for 3 months. Exercise and dietary prescriptions were unchanged during the study. FPG was measured every 4 weeks and IRI was measured by radioimmunoassay before 
and after the treatment with troglitazone or glibenclamide. For estimation of insulin sensitivity, the homeostasis model insulin resistance index (HOMA-R) (FPG $\times$ IRI/22.5) was calculated22,23 ATP-stress ${ }^{201} \mathrm{Tl}$ myocardial scintigraphy was conducted before and after the treatments. The protocol of the study was approved by the Investigational Review Board of the hospital, and the study was conducted in compliance with the Helsinki Declaration. All subjects gave informed consent before enrollment into the study.

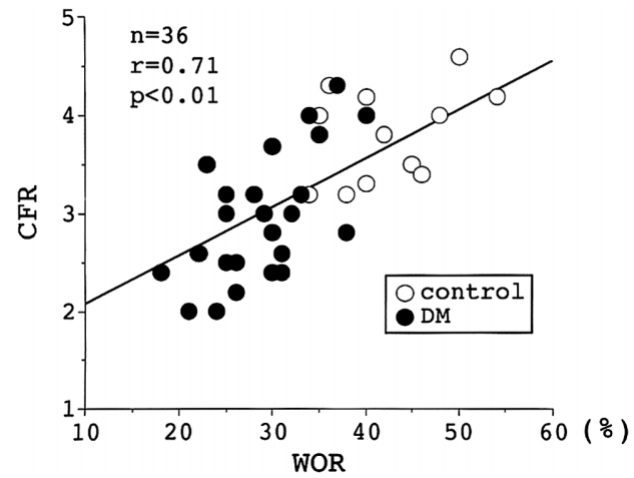

Fig 1. Relationship between coronary flow reserve (CFR) and washout rate (WOR).

\section{Echocardiography}

Left ventricular wall thickness and dimensions, and left ventricular mass were calculated from 2-dimensional echocardiograms using a previous described algorithm, according to the recommendations of the American Society of Echocardiography 24 Left ventricular ejection fraction was also calculated according to the American Society of Echocardiography criteria by the area-length method 25

\section{ATP-Stress Thallium-201 Myocardial Scintigraphy}

The details of the procedure have been described previously! ${ }^{17}$ ATP was infused for 3 min through a peripheral venous catheter for $5 \mathrm{~min}$ at the rate of $0.16 \mathrm{mg} \cdot \mathrm{kg}^{-1} \cdot \mathrm{min}^{-1}$. Next, $111 \mathrm{MBq}(3 \mathrm{mCi})$ of ${ }^{201} \mathrm{Tl}$ were injected as a bolus into another venous site, and the infusion of ATP was continued for an additional $2 \mathrm{~min} .{ }^{201} \mathrm{Tl}$ imaging was performed using a large field of view rotating gamma camera equipped with a low-energy, high-resolution collimator interfaced to a computer (Toshiba GMS-550U, Tokyo Japan). Tomographic reconstruction at $7 \mathrm{~min}$ (initial image) and $4 \mathrm{~h}$ (delayed image) after ${ }^{201} \mathrm{Tl}$ injection was performed and quantified by computerized 2-dimensional polar (Bull's eye) maps of radionuclide activity. The myocardial washout rate was defined as the percent change in activity from the initial to the delayed images within the left ventricle and calculated as: washout rate $(\%)=(\mathrm{A}-\mathrm{B}) / \mathrm{A} \times 100$, where $\mathrm{A}=$ average count/pixel in the left ventricle on the initial image and $B=$ average count/pixel in same region on the delayed image.

Table 1 Baseline Characteristics and Echocardiographic Data

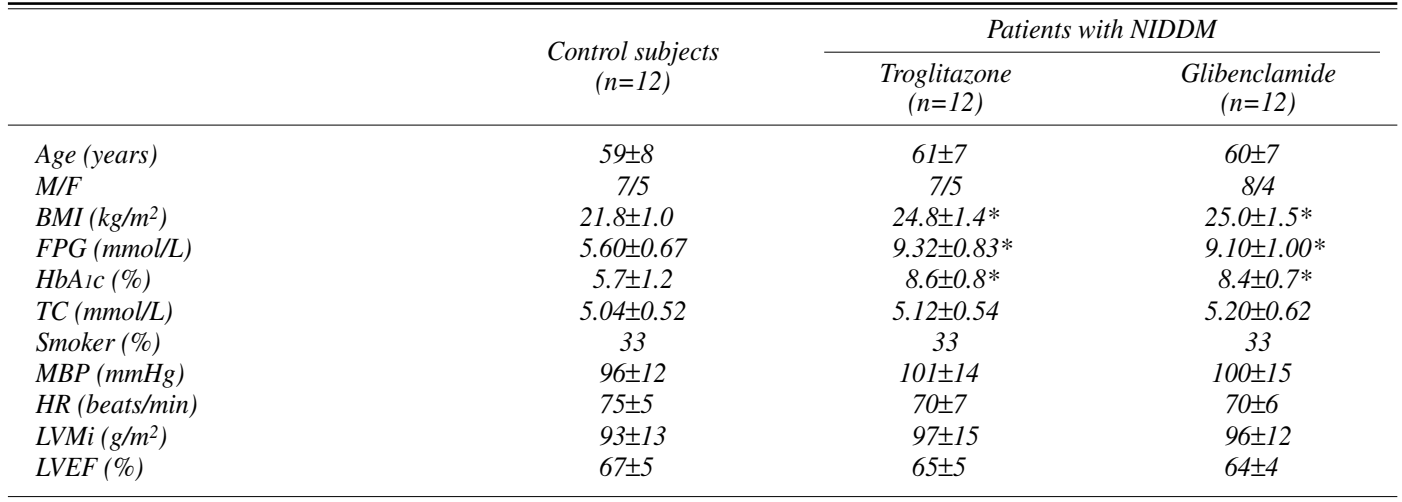

Value are mean $\pm S D .{ }^{*} p<0.01$ vs control subjects. NIDDM, non-insulin-dependent diabetes mellitus; BMI, body mass index; FPG, fasting plasma glucose; MBP, mean blood pressure; TC, total cholesterol; HR, heart rate; LVMi, left ventricular mass index; LVEF, left ventricular ejection fraction.
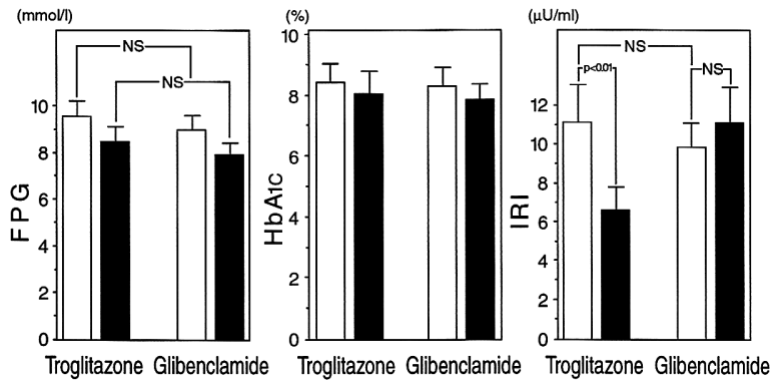

Fig 2. Changes in the fasting plasma glucose (FPG) (Left), hemoglobin Aic ( $\mathrm{HbAlc}_{1}$ (Middle), and plasma insulin level (IRI) (Right) before (open bar) and after (solid bar) treatment with troglitazone or glibenclamide.

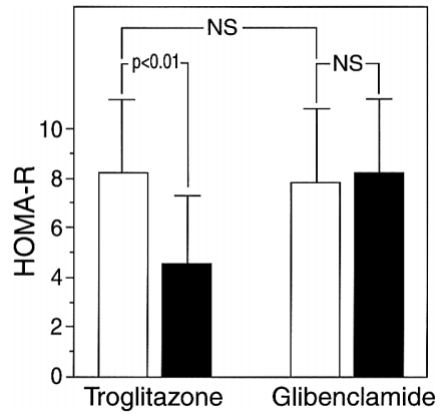

Fig 3. Change in the homeostasis model insulin resistance index (HOMA-R) before (open bar) and after (solid bar) treatment with troglitazone or glibenclamide. 


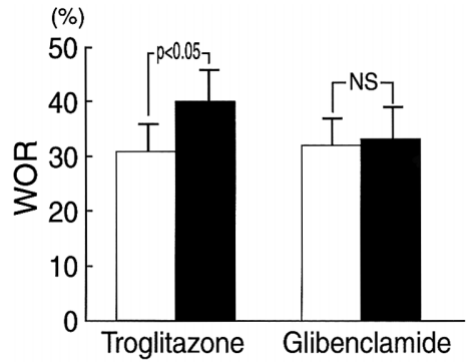

Fig 4. Change in the washout rate (WOR) before (open bar) and after (solid bar) treatment with troglitazone or glibenclamide.

Because the initial ${ }^{201} \mathrm{Tl}$ distribution reflects a relative rather than an absolute reduction in myocardial blood flow, no myocardial abnormality was seen in diabetic patients in this study, all of whom may have homogeneous underperfusion of all myocardial regions. The myocardial washout rate has been analyzed in a nonrelative fashion to indicate diffuse hypoperfused myocardium that shows no perfusion defects. ${ }^{19-21,26}$ We evaluated the relationship between the myocardial washout rate and coronary flow reserve in the study patients within 2 weeks before randomization. According to our previous report ${ }^{18}$ coronary flow reserve is obtained from the ratio of ATP-induced (intravenous infusion at rate of $0.16 \mathrm{mg} \cdot \mathrm{kg}^{-1} \cdot \mathrm{min}^{-1}$ ) hyperemic to baseline time-averaged peak velocity, and as shown in Fig 1, a significant relation was observed $(\mathrm{r}=0.71, \mathrm{p}<0.01)$. Therefore, washout rate was used as the non-invasive evaluation of coronary circulation.

\section{Statistical Analysis}

Data are expressed as mean \pm SEM. Differences between 2 groups were assessed by paired t test with 2 tails, and those among groups were assessed by analysis of variance followed by Bonferroni's test. Statistical significance of changes in FPG, IRI, hemoglobin (Hb) A1c, HOMA-R, and washout rate by the treatments were assessed by analysis of variance for repeated measures. Simple least-sequences regression analysis was used to assess the correlation between 2 variables. A value of $\mathrm{p}<0.05$ was regarded as significant.

\section{Results}

\section{Baseline Characteristics (Table 1)}

There were no significant differences in age, sex, heart rate, coronary risk factors other than DM, left ventricular mass index, and ejection fraction among the 3 groups, and no difference in body mass index, FPG, and HbAic were recognized between the diabetic groups.

\section{Changes in FPG, HbAlc, IRI, and HOMA-R}

None of the patients were withdrawn during this study. The changes in FPG, HbAic, and IRI are shown in Fig 2. Treatment with either troglitazone or glibenclamide for 3 months produced a similar reduction of FPG and $\mathrm{HbA} 1 \mathrm{c}$. IRI was not significantly but tended to be increased by glibenclamide, whereas it was decreased significantly by troglitazone. HOMA-R was also decreased significantly by troglitazone, but not by glibenclamide (Fig 3).

Washout Rate in ATP-Stress Thallium-201

Myocardial Scintigram

Baseline washout rates were $42 \pm 5 \%$ in controls, $30 \pm 4 \%$

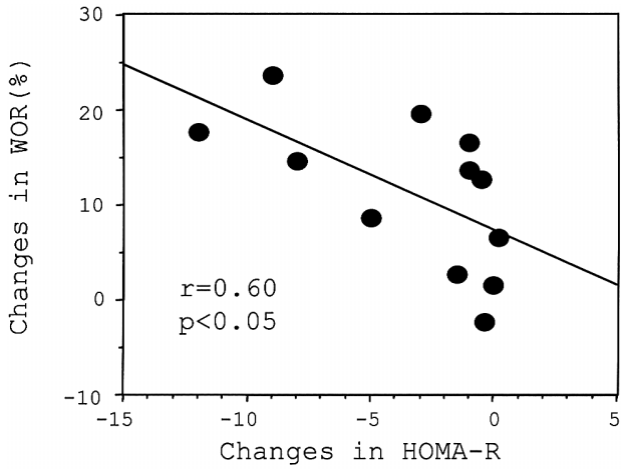

Fig 5. Correlation between the changes in the homeostasis model insulin resistance index (HOMA-R) and washout rate (WOR) in the patients treated with troglitazone.

in the troglitazone-treated group and $32 \pm 4 \%$ in the glibenclamide-treated group. The diabetic patient groups showed significantly lower washout rates than the control group. Heart rate, blood pressure, ejection fraction and serum creatinine were unchanged by the treatments in the diabetic groups. Fig 4 shows the washout rates before and 3 months after the drug treatments. In the troglitazone group, the washout rate was significantly improved, but not in the glibenclamide group. As shown in Fig 5, the increase in washout rate at the end-point of treatment from baseline correlated significantly with the decrease in HOMA-R.

\section{Discussion}

The present study demonstrated that troglitazone improved coronary circulation in the patients with NIDDM with insulin resistance and the improvement in washout rate correlated with a decrease of HOMA-R. Furthermore, glibenclamide did not improve the washout rate despite a similar reduction of FPG. This suggests that the beneficial effects of troglitazone on coronary circulation might be a result of improving insulin resistance rather than reducting the blood sugar level.

In the present diabetic patients, coronary microvascular disease may have been caused by hyperglycemia, as well as by hyperinsulinemia. Hyperglycemia induces advanced glycation end-products, activation of protein kinase $\mathrm{C}$, and disturbance of the polyol metabolism pathway, resulting in oxidative stress in vascular vessel walls. ${ }^{27-29}$ The enhanced cellular oxidative stress reduces nitric oxide and activates nuclear factor $\mathrm{b}$ in endothelial cells 30,31 which may stimulate proliferation of vascular smooth muscle cells and increase vasotonus, so-called vascular remodeling. The intensive management of hyperglycemia prevents the development and progression of cardiovascular complications in insulin-dependent DM in report of the DCCT study 32 and Yokoyama et al also reported that blood glucose concentration rather than insulin resistance was the main cause of the reduced coronary flow reserve in NIDDM patients. 33 However, in their study, treatment with sulfonylurea did not improve coronary circulation despite an adequate reduction in FPG and a decrease in $\mathrm{HbA} 1 \mathrm{c}$, for reasons that are unclear, although there are 2 possible causes. One cause might be the pharmacological action of sulfonylurea itself. Sulfonylurea, while promoting the release of insulin through a blockade of the metabolism-regulated ATP-sensitive potassium channels present in pancreas B-cell membranes, also blocks those 
channels present in coronary vasculature, ${ }^{34-36}$ an action that might prevent coronary vasodilation in response to ATP infusion. Another cause might be the hyperinsulinemia invoked by sulfonylurea. Endogeneous hyperinsulinemia inhibits constitutive nitric oxide synthase and increase free radicals through the activation of NADH/NADPH oxidase activity, resulting in decreased nitric oxide in endothelium. 37 Thus, sulfonylurea might impair endothelium-dependent vasodilation and promote vascular remodeling.

Troglitazone is a newly developed antidiabetic agent that reduces insulin resistance. As confirmed in previous reports, troglitazone decreased blood sugar and plasma insulin level in the present study. In addition, troglitazone improved the washout rate in ATP-stress scintigraphy and the improvement correlated with a decrease in the plasma insulin level. This suggests that triglitazone might improve coronary microvessel disease by improving insulin resistance. Insulin promotes vascular hypertrophy and increases vascular tonus, so troglitazone may restore coronary circulation through the improvement of vasomotor functions by reducing the plasma glucose level as well as the plasma insulin level.

In conclusion, troglitazone may improve coronary circulation and prevent cardiovascular complication effectively in patients with NIDDM.

\section{References}

1. Zoneraich S: Angina pectoris in diabetic patients with normal coronary arteries. JAMA 1979; 234: 241-251

2. Hamby RI, Zoneraich S, Sheman L: Diabetic cardiomyopathy. JAMA 1974; 229: $1749-1754$

3. Fein FS, Sonnenblick EH: Diabetic cardiomyopathy. Prog Cardiovasc Dis 1985; 27: 255-270

4. Attali JR, Sachs RN, Valensi P, Palsky D, Tellier P, Vulpillat M, et al: Asymptomatic diabetic cardiomyopathy: A noninvasive study. Diabetes Res Clin Pract 1988; 4: 183-190

5. Giacomelli E, Wiener J: Primary myocardial disease in the diabetic mouse; an ultrastructural study. Lab Invest 1979; 40: 460-473

6. Hoffman JIE: Maximal coronary flow and the concept of coronary vascular reserve. Circulation 1984; 70: 153-159

7. Nahser PJ, Brown RE, Oskarsson H, Winniford MD, Rossen JD: Maximal coronary flow reserve and metabolic coronary vasodilation in patients with diabetic mellitus. Circulation 1995; 91: 635-640

8. Lash JM, Bohlen HG: Structural and functional origins of suppressed acetylcholine vasodilation in diabetic rat interstinal arterioles. Circ Res 1991; 69: 1259-1266

9. Nitenberg A, Valensi P, Sacns R, Dali M, Aptecar E, Attali JR: Impairment of coronary vascular reserve and Ach-induced coronary vasodilation in diabetic patients with angiographically normal coronary arteries and normal left ventricular systolic function. Diabetes 1993; 42: $1017-1025$

10. Reaven G: Role of insulin resistance in human disease. Diabetes 1988; 37: 1595-1607

11. Cahill GF Jr: Beta-cell deficiency, insulin resistance, or both? (Editorial) N Engl J Med 1988; 318: 1268-1269

12. Stout RW: Insulin and atheroma; 20-year perspective. Diabetes Care 1990; 13: 631-654

13. Rosskopf D, Dusing R, Siffert W: Membrane sodium-proton exchange and primary hypertension. Hypertension 1993; 21: 607-617

14. Fujiwara T, Yoshioka S, Yoshioka T, Ushiyama I, Horikoshi H: Characterization of new oral antidiabetic agent CS-045: Studies in KK and ob/ob mice and Zucker fatty rats. Diabetes 1988; 37: 1549-1558

15. Iwamoto $Y$, Kuzuya $T$, Matsuda $A$, Awata $T$, Kumakura $S$, Inooka G, et al: Effect of new oral antidiabetic agent CS-045 on glucose tolerance and insulin secretion in patients with NIDDM. Diabetes Care 1991; 14: 1083-1086

16. Suter SL, Nolan JJ, Wallace P, Gumbiner B, Olefsky JM: Metabolic effects of new oral hypoglycemic agent CS-045 in NIDDM subjects. Diabetes Care 1992; 15: 193-203
17. Miyagawa M, Kumano S, Sekiya M, Watanabe K, Akutsu H, Imati T, et al: Thallium-201 myocardial tomography with intravenous infusion of adenosine triphosphate in diagnosis of coronary artery disease. $J$ Am Coll Cardiol 1995; 26: 1196-1201

18. Watanabe K, Sekiya M, Ikeda S, Miyagawa M, Kinoshita M, Kumano $\mathrm{S}$ : Comparison of adenosine triphosphate and dipyridamole in diagnosis by thallium-201 myocardial scintigraphy. J Nucl Med 1997; 38: $577-581$

19. Beller GA, Holzgrefe HH, Watson DD: Intrinsic washout rates of thallium-201 in normal and ischemic myocardium after dipyridamole-induced vasodilation. Circulation 1985; 71: 378-386

20. Nishiyama H, Adolph RJ, Gabel M, Lukes SJ, Franklin D, William CC: Effect of coronary blood flow on thallium-201 uptake and washout. Circulation 1982; 65: 534-542

21. Sakata K, Yoshida H, Sugino H, Iimura M, Matsunaga Y, Ono N, et al: Assessment of quantitative exercise thallium-201 emission computed tomography in patients with vasospastic angina: Value of washout rate analysis. Jpn Circ J 1994; 58: 379-388

22. Cleland SJ, Petrie JR, Morris AD, Ueda S, Dorrian CA, Connell JMC: FIRI: A fair insulin resistance index. Lancet 1996; 347: 770

23. Nagasaka S, Iwamoto Y, Ishikawa S, Kuzuya T, Saito T: Efficacy of troglitazone measured by insulin resistance index. Lancet 1997; 350: 184

24. Brad BF III, Wahr D, Wang YS, Bouchard A, Schiller NB: Left ventricular mass and volume/mass ratio determined by two-dimensional echocardiography in normal adults. J Am Coll Cardiol 1985; 6: $1021-1025$

25. Schiller NB, Shah PM, Crawford M: Recommedations for quantitation of the left ventricle by two-dimensional echocardiography. J Am Soc Echocardiogr 1989; 2: 348-367

26. Bateman TM, Maddahi J, Gray RJ, Murphy FL, Garcia EV, Conklin CM, et al: Diffuse slow washout of myocardial thallium-201: A new scintigraphic indicator of extensive coronary artery disease. $J \mathrm{Am}$ Coll Cardiol 1984; 4: 55-64

27. Taniguchi N, Kaneto H, Asahi M, Takahashi M, Wenyi C, Higashiyama S, et al: Involvement of glycation and oxidative stress in diabetic macroangiopathy. Diabetes 1996; 45: S81-S83

28. Hampel A, Maasch C, Heitze U, Lindschau C, Dietz R, Luft FC, et al: High glucose concentrations increase endothelial cell permeability via activation of protein kinase C alpha. Circ Res 1997; 81: 363-371

29. Williamson JR, Chang K, Frangos M, Hasan KS, Ido Y, Kawamura T, et al: Hyperglycemic pseudohypoxia and diabetic complications. Diabetes 1993; 42: 801-813

30. Hsueh WA, Quinones MJ, Creager MA: Endothelium in insulin resistance and diabetes. Diabetes Rev 1997; 5: 343-352

31. Yan SD, Schmidt AM, Anderson GM, Zhang J, Brett J, Zou YS, et al: Enhanced cellular oxidant stress by the interaction of advanced glycation end products with their receptors/binding proteins. J Biol Chem 1994; 269: 9889-9897

32. The Diabetes Control and Complications Trial Research Group: The effect of intensive treatment of diabetes on the development and progression of long term complications in insulin-dependent diabetes mellitus. N Engl J Med 1993; 329: 977-986

33. Yokoyama I, Ohtake T, Momomura S, Yonekura K, Woo-soo S, Nishikawa J, et al: Hyperglycemia rather than insulin resistance is related to reduced coronary flow reserve in NIDDM. Diabetes 1998; 47: $119-124$

34. Brady PA, Terzic A: The sulfonylurea controversy: More questions from the heart. J Am Coll Cardiol 1998; 31: 950-956

35. Fosset M, De Weille JR, Green RD, Schmid-antomarchi H, Lazdunski M: Antidiabetic sulfonylureas control action potential properties in heart cells via high affinity receptors that are linked to ATP-dependent $\mathrm{K}^{+}$channels. J Biol Chem 1988; 263: $7933-7936$

36. Cleveland JC Jr, Meldrum DR, Cain BS, Banerjee A, Harkem AH: Oral sulfonylurea hypoglycemic agents prevent ischemic preconditioning in human myocardium: Two paradoxes revisited. Circulation 1997; 96: $29-35$

37. Shinozaki K, Nishio Y, Hidaka H, Maeno Y, Maegawa H, Kashiwagi A, et al: Endothelial cell specific activation of NADH and NADPH oxidase activity in aorta of hyperinsulinemic animals. Diabetes 1997; 46: $111 \mathrm{~A}$

38. Reaven GM, Lithell H, Landsberg L: Hypertension and associated metabolic abnormalities: The insulin resistance and sympathorenal system. N Engl J Med 1996; 334: 374-381 